\title{
SISTEM PAKAR UNTUK MENDIAGNOSIS GANGGUAN MENTAL PADA ANAK MENGGUNAKAN METODE FORWARD CHAINING DAN CERTAINTY FACTOR
}

\author{
(Expert System for Diagnosing Childhood Mental Disorders using Forward Chaining \\ and Certainty Factor Method)
}

\author{
Salma Nabilla Ulpa*, Fitri Bimantoro \\ Dept Informatics Engineering, Mataram University \\ Jl. Majapahit 62, Mataram, Lombok NTB, INDONESIA \\ Email: salmanabilla22@gmail.com, bimo@unram.ac.id
}

\begin{abstract}
Mental health problems in children, such as stress, anxiety, or depression are real and they are just as important as their physical health problems, but many children don't get the care they deserve. In practice, psychology mostly still uses the questionnaire method or a series of questions. This method is considered less effective and efficient because it is still done manually, so an artificial intelligence technology such as an expert system is needed so that it can help diagnose mental disorders in children early. This research developed an expert system to diagnose mental disorders in children using the mobile-based Forward Chaining and Certainty Factor method that diagnoses 7 types of mental disorders in children from 46 symptoms obtained based on the knowledge of 3 experts. Based on the results of the black box testing states that the expert system that was built has had compatibility in terms of functionality. The results of the theoretical calculation test states that the calculation system of an expert diagnosis of a child's mental disorder is in accordance with the results of calculations done manually. In testing the accuracy of the system from 30 cases tested on 3 experts, the expert system that was built succeeded in producing system accuracy values based on the final belief value of the three experts, based on the belief values of experts 1, 2, and 3, respectively 91.11\%, 96.67\%, 96.67\% and 80\%. Furthermore, the results of MOS testing conducted on 35 respondents produce MOS of 4.12 from a scale of 5 where based on that value the expert system built is categorized into a good system.
\end{abstract}

Keywords: Expert System, Mental Disorders, Forward Chaining, Certainty Factor, Mobile

*Penulis Korespondensi

\section{Pendahuluan}

Masalah kesehatan mental pada anak, yang terdiri dari stres, kecemasan, atau depresi dan sebagainya merupakan sesuatu yang nyata dan masalah tersebut jika dikaitkan dengan masalah fisik anak hal tersebut sama pentingnya. Namun, banyak anak penderita gangguan mental yang tidak mendapatkan perawatan yang tepat. Tercatat sebanyak 30 kasus pada tahun 2017 dan 40 kasus pada tahun 2018 yang menderita gangguan mental masa kanak berdasarkan data yang diperoleh dari hasil wawancara penulis dengan salah satu dokter spesialis kejiwaan di Rumah Sakit Jiwa Mutiara Sukma Provinsi NTB. Tidak menutup kemungkinan bahwa penderita gangguan mental pada anak akan terus bertambah setiap tahunnya. Hal ini tentu akan memengaruhi tumbuh kembang perilaku anak hingga dewasa nanti [1].
Dalam ilmu psikologis, metode yang diterapkan dalam proses memahami dan mempelajari sisi psikologis manusia masih dilakukan secara manual yaitu dengan metode quesioner atau serangkaian pertanyaan [2]. Metode ini dirasa kurang efektif dan efisien karena metode tersebut sukar dicari validitasnya.

Untuk mempermudah melakukan diagnosa penyakit gangguan mental pada anak dibutuhkan sebuah teknologi kecerdasan buatan seperti sistem pakar yang merupakan bagian dari ilmu komputer yang mengadopsi pengetahuan manusia dan membuat agar mesin (komputer) dapat menyelesaikan masalah seperti sebaik yang dilakukan oleh para ahli. Penelitian ini mengembangkan sistem pakar untuk mendiagnosis gangguan mental anak menggunakan metode Forward Chaining dan Certainty Factor berbasis mobile. Metode Certainty Factor dalam penelitian ini merupakan metode yang digunakan untuk mengukur 
ketidakpastian dalam mendiagnosis dan mengidentifikasi suatu penyakit sedangkan metode Forward Chaining digunakan untuk pengambilan kesimpulan dengan alur maju. Sistem pakar ini dapat digunakan sebagai alat bantu untuk mendiagnosis gangguan mental secara dini pada anak, dan juga menghasilkan informasi yang tepat mengenai penyebab dan saran penanganan dari penyakit gangguan mental yang dialami. Terdapat penelitian yang menghasilkan sistem pakar dengan hasil yang tingkat akurasinya tinggi, yang diperoleh berdasarkan bobot gejala yang dipilih pengguna. Pemilihan bobot gejala oleh pengguna ini sangat berpengaruh terhadap akurasi sistem, karena dilakukan sesuai dengan kondisi pengguna itu sendiri [3]. Oleh karena itu untuk dapat mendiagnosis secara dini gangguan mental pada anak, maka dibangun sebuah sistem pakar untuk mendiagnosis gangguan mental pada anak menggunakan metode Forward Chaining dan Certainty Factor berbasis mobile.

\section{TINJAUAN PUSTAKa dAN DASAR TEORI}

\subsection{Tinjauan Pustaka}

Penelitian yang membahas mengenai sistem pakar gangguan mental pada anak telah dilakukan oleh beberapa peneliti sebelumnya [4][5]. Penelitian tentang analisis penerapan metode bayesian network untuk mendiagnosa penyakit gangguan mental pada anak menghasilkan sistem berbasis website yang dapat mendiagnosis sebanyak 7 jenis gangguan mental pada anak [4]. Kelebihan sistem ini yaitu setelah proses pengujian menghasilkan akurasi yang cukup tinggi yaitu berdasarkan pengetahuan 2 pakar yaitu sebesar 95\%. Pada penelitian yang membahas sistem pakar gangguan mental pada anak dengan metode Dempter Shafer [5]. Penelitian ini menghasilkan sistem berbasis website yang dapat mendiagnosis 8 jenis gangguan mental pada anak. Kelebihan dari sistem ini yaitu menghasilkan tingkat akurasi sebesar $95 \%$ berdasarkan analisis 3 orang pakar. Penelitian selanjutnya yang membahas sistem pakar gangguan mental pada anak dengan metode Certainty Factor. Sistem yang dihasilkan yaitu berbasis desktop yang dapat mendiagnosis 3 jenis penyakit mental pada anak yaitu, Retradasi Mental, Autis, dan Conduct Disorder untuk anak usia 3-10 tahun [6]. Sistem ini memiliki kelebihan yaitu pasien dapat memilih jawaban dengan tingkat keyakinan tertentu (tidak yakin, tidak tahu, dan sangat yakin) sesuai dengan yang dirasakan.

Penelitian selanjutnya yaitu membahas mengenai perbandingan metode Naïve Bayes dan Certainty Factor untuk diagnosa penyakit jagung [7].
Berdasarkan hasil pengujian, sistem yang menggunakan metode Certainty Factor memiliki persentase kebenaran yang lebih baik daripada menggunakan metode Naïve Bayes. Hasil percobaan menunjukkan akurasi hingga $80 \%$. Pada penelitian yang membandingkan beberapa metode (Certainty Factor, Dempster Shafer dan Teorema Bayes) untuk mengidentifikasi penyakit inflamasi dermatitis imun pada anak, melakukan perbandingan antar metode agar mengetahui metode mana yang paling tepat dalam melakukan diagnosis penyakit [8]. Sehingga diperoleh hasil pada perhitungan dengan metode Certainty Factor dengan nilai probabilitas 0.80 lebih tinggi dari 2 metode lainnya.

Penelitian yang membahas sistem pakar untuk mendiagnosis tingkat gangguan kepribadian histerik dengan metode Certainty Factor [9]. Berdasarkan hasil pengujian akurasi yang dilakukan, diperoleh hasil sebesar $83,3 \%$. Hal ini menunjukkan bahwa hasil uji antara sistem pakar dan pakarnya sudah sesuai. Pada penelitian yang membahas penerapan metode Forward Chaining dan Certainty Factor untuk diagnosa hama anggrek menghasilkan tingkat akurasi sebesar 93,0736\% hal ini menunjukkan bahwa metode Forward Chaining dan Certainty Factor sangat cocok jika dikombinasikan untuk dapat menyelesaikan permasalahan karena akurasi yang dihasilkan diatas 90\% [3]. Penelitian selanjutnya yaitu tentang sistem pakar untuk diagnosis mental disorder menggunakan metode Forward Chaining dimana hasil akurasi dari penelitian tersebut yaitu $96 \%$. Keakuratan penelitian tersebut diperoleh dari uji pemeriksaan 100 pasien secara acak yang diperoleh hanya 4 deteksi yang gagal [10].

Berdasarkan beberapa penelitian yang sudah ditinjau dan dianalisis tersebut maka dibangun suatu sistem pakar yang dapat mendiagnosis gangguan mental pada anak, dimana untuk mengukur ketidakpastian dalam mendiagnosis dan mengidentifikasi suatu penyakit digunakan metode Certainty Factor untuk memberikan persentase dari hasil diagnosis sistem yang didapatkan dari perhitungan berdasarkan bobot gejala yang dipilih pengguna dan memperhatikan gejala-gejala gangguan mental pada anak menggunakan metode Forward Chaining untuk kaidah dengan premis atau gejala tunggal, sehingga penyebab dan saran penanganan dari suatu gangguan mental anak dapat diberikan kepada pengguna secara tepat. 


\subsection{Dasar Teori}

Berikut merupakan teori penunjang yang melandasi pemecahan masalah dalam sistem ini, yaitu sistem pakar, Forward Chaining, Certainty Factor, dan Flutter.

\subsubsection{Sistem Pakar}

Sistem pakar merupakan sistem yang menerjemahkan atau dapat meniru kemampuan manusia ke dalam sistem komputer dengan menggunakan teknik tertentu, sehingga sistem tiruan dapat melakukan suatu penyelesaian masalah seperti layaknya seorang ahli atau dapat disebut sebagai pakar. Sistem pakar dapat disusun menjadi beberapa komponen berupa kombinasi kaidah-kaidah penarikan kesimpulan atau inference rules yang berisi suatu basis pengetahuan, basis pengetahuan tersebut diperoleh dari satu atau lebih pakar yang memiliki bidang tertentu. Kombinasi inference rules pada sistem pakar akan dikumpulkan dan disimpan dalam komputer agar dapat digunakan untuk proses penarikan kesimpulan dari suatu masalah tertentu [11].

\subsubsection{Forward Chaining}

Forward chaining atau disebut juga penalaran ke depan, merupakan metode penarikan kesimpulan yang dimulai dari suatu data atau fakta yang ada lalu bergerak maju menuju kesimpulan melalui premispremis yang sudah ditentukan (bottom up reasoning). Forward chaining melakukan pencarian dari suatu masalah yang ada menuju ke solusinya [12]. Gambaran mengenai pola dari metode forward chaining dapat dilihat pada Gambar 1.

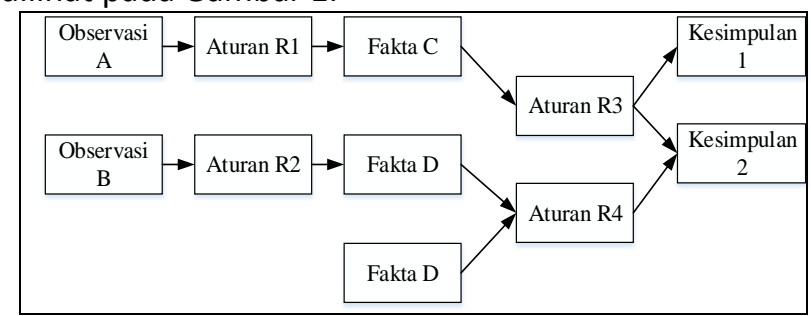

Gambar 1. Pola forward chaining

\subsubsection{Certainty Factor}

Dalam membangun sebuah sistem pakar, selain menggunakan metode penarikan kesimpulan dibutuhkan sebuah metode pendekatan perhitungan agar dapat menghasilkan akurasi dari kesimpulan yang sudah diperoleh. Sistem pakar harus mampu bekerja dalam ketidakpastian karena basis pengetahuan yang dikumpulkan diperoleh berdasarkan nilai ketidakpastian yang dari pakar. Salah satu metode untuk menyelesaikan masalah ketidakpastian adalah metode Certainty Factor [13]. Certainty Factor menyatakan kepercayaan dalam sebuah kejadian (atau fakta atau hipotesis) berdasarkan penilaian yang diperoleh dari pakar yang dinyatakan sebagai nilai belief [11].

Nilai yang digunakan dalam metode Certainty Factor ini menyatakan derajat keyakinan seorang pakar atau lebih terhadap suatu data. Dalam metode Certainty Factor, ditekankan suatu konsep keyakinan dan ketidakyakinan yang kemudian dapat dibentuk suatu formulasi rumusan dasar seperti Persamaan (1) berikut:

Dimana

$$
C F(H, E)=M B(H, E)-M D(H, E)
$$

$C F(H, E): \quad$ Certainty Factor dari hipotesis $H$ yang dipengaruhi oleh gejala (evidence) $E$.

$M B(H, E)$ : Ukuran kenaikan kepercayaan (measure of increased belief) terhadap hipotesis $H$ yang dipengaruhi oleh gejala $E$.

$M D(H, E)$ : Ukuran kenaikan ketidak- percayaan (measure of increased disbelief) terhadap hipotesis $H$ yang dipengaruhi oleh gejala $E$.

Bentuk rumus Certainty Factor berdasarkan sebuah aturan JIKA $E$ MAKA $H$ ditunjukkan seperti Persamaan (2) sebagai berikut:

$$
C F(H, e)=C F(E, e) * C F(H, E)
$$

Dimana,

$C F(H, e): \quad C F$ hipotesis yang dipengaruhi oleh evidence $E$.

$C F(E, e): \quad C F$ evidence $E$ yang dipengaruhi oleh evidence $e$.

$C F(H, E): \quad C F$ hipotesis dengan asumsi evidence diketahui dengan pasti, yaitu ketika $C F(E, e)=1$.

$C F$ Gabungan atau $C F$ combine dibentuk untuk mendapatkan nilai $C F$ akhir atau nilai yang digunakan sebagai kesimpulan. Nilai $C F$ ini dipengaruhi oleh semua nilai yang diperoleh dari hasil pada perhitungan berdasarkan Persamaan (2) dan beberapa aturan yang menghasilkan kesimpulan tersebut. Adapun rumus perhitungan $C F$ Gabungan yang memiliki 3 persamaan yaitu Persamaan (3), (4), dan (5) ditunjukkan sebagai berikut [13]:

$C F(C F 1, C F 2)=\left\{\begin{array}{l}C F 1+C F 2 *(1-C F 1), C F 1>0 \text { dan } C F 2>0(3) \\ \frac{C F 1+C F 2}{(1-(\min (|C F 1|,|C F 2|)))}, \text { salah satu }(C F 1, C F 2)<0 \\ C F 1+C F 2 *(1+C F 1), C F 1<0 \text { dan } C F 2<0(5)\end{array}\right.$ 
Dimana,

$$
\begin{array}{lrl}
C F 1 & \text { Nilai } C F \text { dari evidence } 1 . \\
C F 2 & : & \text { Nilai } C F \text { dari evidence } 2 . \\
C F(C F 1, C F 2): & \text { Hasil Nilai } C F \text { gabungan dari } \\
& \text { evidence yang ada. }
\end{array}
$$

\subsubsection{Flutter}

Flutter merupakan sebuah kerangka kerja yang digunakan untuk membangun aplikasi mobile yang diciptakan oleh Google dimana developer dapat membuat aplikasi baik untuk sistem operasi android maupun sistem operasi iOS dengan menggunakan bahasa Dart dan source code yang sama. Code yang terdapat pada Flutter ini bersifat open source, yang tersebar dan tersedia bebas untuk didapatkan [14]. Bahasa Dart merupakan salah satu bahasa pemrograman yang dapat digunakan untuk mengembangkan berbagai platform termasuk web, mobile server, dan IoT. Bahasa ini juga merupakan bahasa standar yang digunakan dari Flutter [15].

\section{Metode Penelitian}

Metode penelitian terdiri dari beberapa tahap yang akan dilakukan peneliti untuk mempermudah melakukan penelitian. Dalam metode penelitian ini dilakukan beberapa tahapan yaitu sebagai berikut.

\subsection{Studi Literatur}

Studi literatur merupakan tahap untuk mempelajari aspek-aspek yang berkaitan dengan penelitian serta mengetahui dasar-dasar keilmuan dan perkembangan teknologi terkait dengan penelitian. Diantaranya adalah mencari sumber-sumber literatur yang berkaitan dengan gangguan mental pada anak dan penerapan metode Forward Chaining dan Certainty Factor pada sistem pakar untuk membantu dalam penarikan kesimpulan.

\subsection{Pengumpulan Data}

Tahapan ini dilakukan untuk mengumpulkan datadata terkait gangguan mental pada anak. Data yang dikumpulkan berasal dari hasil wawancara dengan pakar yang berasal dari Rumah Sakit Jiwa Mutiara Sukma Propinsi NTB dan yang menjadi pakar dalam penelitian ini yaitu dokter spesialis gangguan jiwa yang berperan sebagai psikiater konsultan anak dan remaja pada Rumah Sakit Jiwa Mutiara Sukma Propinsi NTB.

Dokter spesialis kejiwaan yang memberikan data gejala berdasarkan buku PPDGJ-III dan DSM IV-TR, diskripsi, penanganan, serta nilai keyakinan gejala gangguan mental pada anak yang banyak ditangani di Rumah Sakit Jiwa Mutiara Sukma adalah dr. Qomarul
Islamiyati, Sp.KJ. Dokter lain yang membantu dalam meberikan nilai keyakinan gejala gangguan mental pada anak yaitu dr. Agustine M. M.Kes.,Sp.KJ. dan dr. Lusiana W., Sp.KJ.

\subsection{Perancangan Sistem}

Perancangan sistem dilakukan untuk menentukan bagaimana suatu sistem akan menyelesaikan suatu permasalahan. Struktur sistem pakar gangguan mental pada anak ditunjukkan oleh Gambar 2.

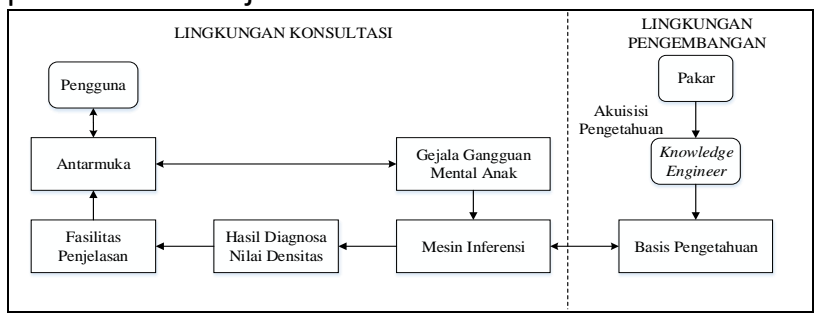

Gambar 2. Arsitektur sistem pakar gangguan mental pada anak [16].

Berikut ini dijelaskan mengenai arsitektur sistem pakar diagnosis gangguan mental pada anak berdasarkan pada Gambar 2.

a. Pengguna, pengguna dalam hal ini yaitu orang tua pasien yang menggunakan sistem untuk melakukan konsultasi mengenai gangguan mental yang dialami oleh anaknya serta mendapatkan informasi untuk solusi penanganan yang bisa dilakukan.

b. Antarmuka merupakan mekanisme yang digunakan oleh pengguna sistem dan sistem pakar agar dapat berkomunikasi.

c. Gejala gangguan mental anak, berdasarkan gejala yang berupa tanda-tanda atau ciri-ciri yang dapat dirasakan pasien penderita gangguan mental, dapat digunakan oleh sistem sebagai masukan dan selanjutnya akan diproses agar menghasilkan hasil diagnosis.

d. Pakar memiliki peranan penting dalam pembangunan sistem ini, dokter spesialis gangguan kejiwaan berperan sebagai pakar untuk dapat memberikan data dan informasi mengenai deskripsi, gejala, penanganan, serta nilai keyakinan setiap gejala gangguan mental pada anak.

e. Akuisisi Pengetahuan, merupakan proses untuk mengumpulkan data pengetahuan mengenai gangguan mental pada anak yang diperoleh dari pakar.

f. Knowledge Engineer, merupakan mekanisme yang digunakan untuk menghubungkan sistem pakar dengan pakarnya agar informasi yang didapatkan dari pakar dapat diterjemahkan 
kemudian dijadikan dasar dalam pembentukan basis pengetahuan.

g. Basis Pengetahuan, merupakan dasar yang digunakan dalam pengambilan keputusan sistem pakar yang mengandung pengetahuan, formulasi dan penyelesaian masalah yang diperoleh dari pakar maupun sumber lain. Aturan dalam basis pengetahuan berbentuk IF-THEN yang berkaitan dengan relasi antara gejala dan jenis gangguan mental anak.

h. Mesin Inferensi (inference engine) merupakan otak dari sistem pakar, dimana di dalamnya dilakukan proses untuk menghasilkan informasi dari fakta yang diketahui. Metode yang digunakan dalam sistem ini adalah Forward Chaining, yaitu dengan memasukkan beberapa data gejala untuk memperoleh kesimpulan dan untuk dapat diketahui persentasenya digunakan metode Certainty Factor.

\subsection{Implementasi Sistem}

Pada tahap implementasi ini dilakukan pembuatan sistem berdasarkan dengan perancangan yang sudah dibuat sebelumnya yang kemudian akan diimplementasikan ke dalam program.

\subsection{Pengujian}

Pengujian sistem bertujuan untuk menemukan error atau ketidaksempurnaan program pada sistem pakar sebelum dikirim kepada pengguna. Pengujian sistem yang dilakukan pada penelitian ini dengan 4 cara yaitu, pengujian black box, pengujian perhitungan teoritis, pengujian akurasi sistem dan pengujian MOS (Mean Opinion Score).

\subsection{Penarikan Kesimpulan}

Penarikan kesimpulan dilakukan apabila semua tahapan penelitian sudah terpenuhi dan sesuai dengan tujuan penelitian serta dapat memberikan informasi sesuai kebutuhan pengguna sistem.

\section{HASIl dan PEMBahasan}

\subsection{Implementasi Sistem Pakar}

Pada implementasi sistem pakar ini akan dibahas mengenai alur kerja sistem beserta antarmuka dari sistem pakar diagnosis gangguan mental pada anak menggunakan metode Certainty Factor yang dibangun. Sistem pakar diagnosis gangguan mental pada anak ini dibangun menggunakan Visual Studio Code sebagai text editor, dan dibangun dengan framework Flutter yang menggunakan bahasa pemrograman Dart. Implementasi sistem pakar gangguan mental anak yaitu seperti Gambar 3 yang merupakan halaman konsultasi yang berisi gejala-gejala pada sistem pakar, hasil diagnosis yang sudah dilakukan sistem, dan halaman detail analisis yang berisi kemungkinankemungkinan penyakit lain yang diderita berdasarkan hasil diagnosis. Pada Gambar 4 merupakan fitur-fitur tambahan yang terdapat pada aplikasi seperti fitur info penyakit, panduan penggunaan dan riwayat konsultasi.

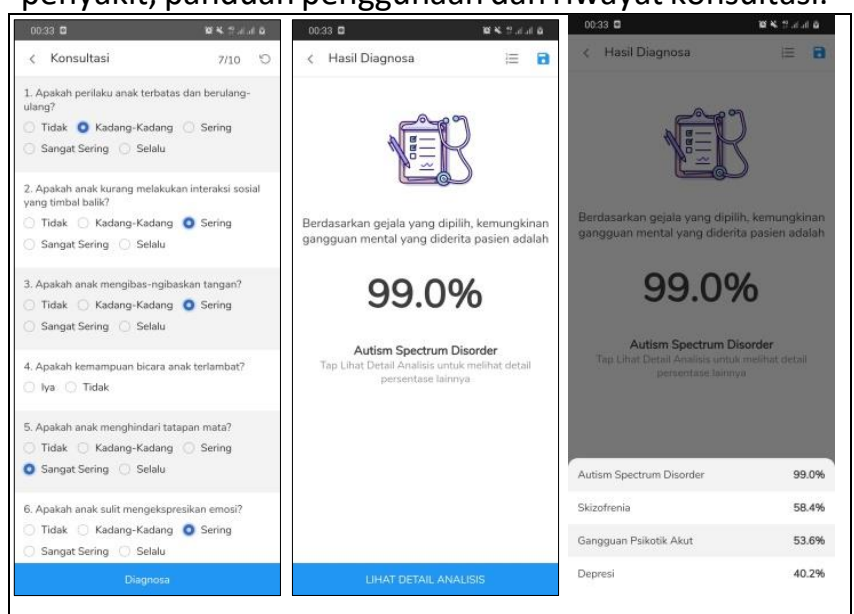

Gambar 3. Fitur diagnosis pada sistem pakar

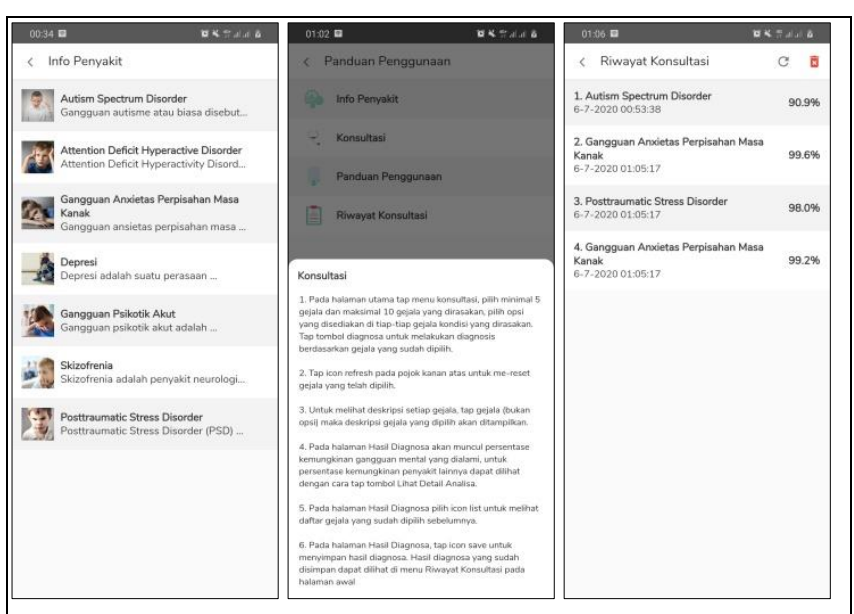

Gambar 6. Fitur tambahan pada sistem pakar

\subsection{Pengujian Black Box}

Pengujian black box bertujuan untuk memeriksa fungsionalitas dari sistem pakar diagnosis gangguan mental pada anak yang dibangun. Pengujian black box dilakukan oleh 5 responden yaitu 5 orang mahasiswa yang berasal dari Program Studi Teknik Informatika, dimana teknis pengujian dilakukan melalui Google Form dengan cara menyerahkan link yang menuju Google Form dan link yang mengarahkan responden menuju halaman Google Drive untuk dapat mengunduh serta melakukan instalasi di ponsel 
masing-masing. Hasil pengujian black box yang diperoleh dapat dilihat pada Tabel I.

TABEL I. HASIL PENGUJIAN BLACK BOX

\begin{tabular}{|l|c|}
\hline \multicolumn{1}{|c|}{ Fungsi } & Hasil Pengujian \\
\hline Fungsi laman info penyakit & Valid \\
\hline Fungsi laman konsultasi & Valid \\
\hline $\begin{array}{l}\text { Fungsi laman panduan } \\
\text { penggunaan }\end{array}$ & Valid \\
\hline Fungsi laman riwayat konsultasi & Valid \\
\hline
\end{tabular}

Berdasarkan hasil pengujian black box yang dilakukan sesuai pada Tabel I dapat disimpulkan bahwa sistem pakar gangguan mental pada anak dengan metode Forward Chaining dan Certainty Factor yang dibangun segi fungsionalitasnya telah berjalan sebagaimana mestinya karena telah memberikan hasil sesuai dengan yang diharapkan.

\subsection{Pengujian Perhitungan Teoritis}

Pengujian perhitungan teoritis dilakukan dengan cara menyesuaikan hasil perhitungan program sistem pakar dengan hasil perhitungan secara teoritis dengan metode certainty factor. Pengujian ini dilakukan dengan tujuan untuk mengetahui apakah hasil persentase perhitungan sistem sesuai dengan hasil perhitungan manual yang dilakukan pada 1 contoh kasus yang dapat dilihat pada Tabel II.

TABEL II. HASIL PENGUIIAN PERHITUNGAN TEORITIS

\begin{tabular}{|c|c|c|c|}
\hline $\begin{array}{c}\text { Kode } \\
\text { penyakit }\end{array}$ & $\begin{array}{c}\text { CF } \\
\text { pakar }\end{array}$ & $\begin{array}{l}\text { CF } \\
\text { User }\end{array}$ & Gejala \\
\hline \multirow{3}{*}{$\begin{array}{l}\text { [P1] Autism } \\
\text { Spectrum } \\
\text { Disorder }\end{array}$} & 0.73 & 0.6 & $\begin{array}{l}\text { Anak berperilaku } \\
\text { menyendiri }\end{array}$ \\
\hline & 0.53 & 0.8 & $\begin{array}{l}\text { Anak mudah terbawa } \\
\text { suasana hati }\end{array}$ \\
\hline & 0.73 & 1.0 & $\begin{array}{l}\text { Anak sering melakukan } \\
\text { pengulangan kata-kata } \\
\text { serta kalimat-kalimat }\end{array}$ \\
\hline \multirow{2}{*}{$\begin{array}{c}\text { [P2] } \\
\text { Attention } \\
\text { Deficit } \\
\text { Hyper- } \\
\text { active } \\
\text { Disorder }\end{array}$} & 0.87 & 0.6 & $\begin{array}{l}\text { Anak sering meninggalkan } \\
\text { kegiatan sebelum } \\
\text { kegiatan itu selesai }\end{array}$ \\
\hline & 0.80 & 0.4 & $\begin{array}{l}\text { Anak mengalami } \\
\text { kegelisahan yang } \\
\text { berlebihan }\end{array}$ \\
\hline \multirow{2}{*}{$\begin{array}{c}\text { [P3] } \\
\text { Gangguan } \\
\text { Anxietas } \\
\text { Perpisahan } \\
\text { Masa Kanak }\end{array}$} & 0.73 & 0.8 & $\begin{array}{l}\text { Anak terus menerus } \\
\text { enggan atau menolak ke } \\
\text { sekolah }\end{array}$ \\
\hline & 0.87 & 0.8 & $\begin{array}{l}\text { Anak terus menerus } \\
\text { enggan atau menolak } \\
\text { tidur tanpa ditemani } \\
\text { orang terdekat? }\end{array}$ \\
\hline
\end{tabular}

TABEL II. LANJUTAN

\begin{tabular}{|c|c|c|l|}
\hline $\begin{array}{c}\text { Kode } \\
\text { penyakit }\end{array}$ & $\begin{array}{c}\text { CF } \\
\text { pakar }\end{array}$ & $\begin{array}{c}\text { CF } \\
\text { User }\end{array}$ & \multicolumn{1}{|c|}{ Gejala } \\
\hline [P4] Depresi & 0.67 & 0.8 & $\begin{array}{l}\text { Anak mudah terbawa } \\
\text { suasana hati }\end{array}$ \\
\hline $\begin{array}{c}\text { [P5] } \\
\text { Gangguan } \\
\text { Psikotik Akut }\end{array}$ & 0.67 & 0.6 & $\begin{array}{l}\text { Anak berperilaku } \\
\text { menyendiri }\end{array}$ \\
\hline $\begin{array}{c}\text { [P6] } \\
\text { Skizofrenia }\end{array}$ & 0.73 & 0.6 & $\begin{array}{l}\text { Anak berperilaku } \\
\text { menyendiri }\end{array}$ \\
\hline
\end{tabular}

a. Mencari persentase untuk penyakit [P1] Autism Spectrum Disorder Menghitung CF Gejala 1 (Apakah anak berperilaku menyendiri?)

$$
\begin{aligned}
& C F[H, E] 1=C F(\text { user }) * C F(\text { pakar }) \\
& C F[H, E] 1=0.73 * 0.6 \\
& C F[H, E] 1=0.438
\end{aligned}
$$

Menghitung CF Gejala 2 (Apakah anak mudah terbawa suasana hati?)

$C F[H, E] 2=C F($ user $) * C F($ pakar $)$

$C F[H, E] 2=0.53 * 0.8$

$C F[H, E] 2=0.424$

Menghitung CF Gejala 3 (Apakah anak sering melakukan pengulangan kata-kata serta

kalimat-kalimat?)

$C F[H, E] 3=C F($ user $) * C F($ pakar $)$

$C F[H, E] 3=0.73 * 1.0$

$C F[H, E] 3=0.73$

Menghitung $\mathrm{CF}$ gabungan $\mathrm{CF}[\mathrm{H}, \mathrm{E}] 1$ dan

$\mathrm{CF}[\mathrm{H}, \mathrm{E}] 2$

CF combine $C F[H, E] 1,2$

$=C F[H, E] 1+C F[H, E] 2 *(1-C F[H, E] 1)$

$=0.438+0.424 *(1-0.438)$

$=0.676288$

CF combine CF $[H, E] 1,2,3$

$=C F[H, E] 1,2+C F[H, E] 3 *(1-C F[H, E] 1,2)$

$=0.676288+0.73 *(1-0.676288)$

$=0.913$

Sehingga persentase penyakit [P1] yaitu 0.91

* $100=91.3 \%$

b. Mencari persentase untuk penyakit [P2] Attention Deficit Hyperactive Disorder Menghitung CF Gejala 1 (Apakah anak sering meninggalkan kegiatan sebelum kegiatan itu selesai?)

$C F[H, E] 1=C F($ user $) * C F($ pakar $)$

$C F[H, E] 1=0.87 * 0.6$

$C F[H, E] 1=0.522$

Menghitung CF Gejala 2 (Apakah anak mengalami kegelisahan yang berlebihan?)

$C F[H, E] 2=C F($ user $) * C F($ pakar $)$

$C F[H, E] 2=0.80 * 0.4$ 
$C F[H, E] 2=0.32$

Menghitung $\mathrm{CF}$ gabungan $\mathrm{CF}[\mathrm{H}, \mathrm{E}] 1$ dan

$\mathrm{CF}[\mathrm{H}, \mathrm{E}] 2$

CFcombine $C F[H, E] 1,2$

$=C F[H, E] 1+C F[H, E] 2 *(1-C F[H, E] 1)$

$=0.522+0.32 *(1-0.522)$

$=0.67496$

Sehingga persentase penyakit [P2] yaitu $0.675 * 100=67.5 \%$

c. Mencari persentase untuk penyakit [P3]

Gangguan Anxietas Perpisahan Masa Kanak

Menghitung CF Gejala 1 (Apakah anak terus menerus enggan atau menolak ke sekolah?)

$C F[H, E] 1=C F($ user $) * C F($ pakar $)$

$C F[H, E] 1=0.73 * 0.8$

$C F[H, E] 1=0.584$

Menghitung CF Gejala 2 (Apakah anak terus menerus enggan atau menolak tidur tanpa ditemani orang terdekat?)

$C F[H, E] 2=C F($ user $) * C F($ pakar $)$

$C F[H, E] 2=0.87 * 0.8$

$C F[H, E] 2=0.696$

Menghitung $\mathrm{CF}$ gabungan $\mathrm{CF}[\mathrm{H}, \mathrm{E}] 1$ dan

$\mathrm{CF}[\mathrm{H}, \mathrm{E}] 2$

CFcombine $C F[H, E] 1,2$

$=C F[H, E] 1+C F[H, E] 2 *(1-C F[H, E] 1)$

$=0.584+0.696 *(1-0.584)$

$=0.873536$

Sehingga persentase penyakit [P3] yaitu $0.874 * 100=87.4 \%$

d. Mencari persentase untuk penyakit [P4]

Depresi

Menghitung CF Gejala 1 (Apakah anak mudah terbawa suasana hati?)

$C F[H, E] 1=C F($ user $) * C F($ pakar $)$

$C F[H, E] 1=0.67 * 0.8$

$C F[H, E] 1=0.536$

Sehingga persentase penyakit [P4] yaitu $0.536 * 100=53.6 \%$

e. Mencari persentase untuk penyakit [P5] Gangguan Psikotik Akut

Menghitung CF Gejala 1 (Apakah anak berperilaku menyendiri?)

$C F[H, E] 1=C F($ user $) * C F($ pakar $)$

$C F[H, E] 1=0.67 * 0.6$

$C F[H, E] 1=0.402$

Sehingga persentase penyakit [P5] yaitu $0.402 * 100=40.2 \%$

f. Mencari persentase untuk penyakit [P6]

Skizofrenia

Menghitung CF Gejala 1 (Apakah anak berperilaku menyendiri?)

$C F[H, E] 1=C F($ user $) * C F($ pakar $)$

$C F[H, E] 1=0.73 * 0.6$
$C F[H, E] 1=0.438$

Sehingga persentase penyakit [P6] yaitu $0.438 * 100=43.8 \%$

Berdasarkan 6 kemungkinan penyakit dan 6 gejala yang dipilih pengguna maka dihasilkan penyakit yang memiliki persentase terbesar yaitu penyakit [P1] Autism Spectrum Disorder sebesar 91.3\%.

Hasil konsultasi yang dilakukan sistem ketika dimasukkan 7 gejala yang terdapat pada Tabel II dapat dilihat pada Gambar 9. Sistem memberikan hasil diagnosa berdasarkan gejala yang sudah dipilih, kemungkinan gangguan mental yang diderita pasien yaitu Autism Spectrum Disorder dengan persentase 91.3\%, sehingga disimpulkan hasil perhitungan sistem sudah sesuai dengan hasil perhitungan manual atau teoritis.

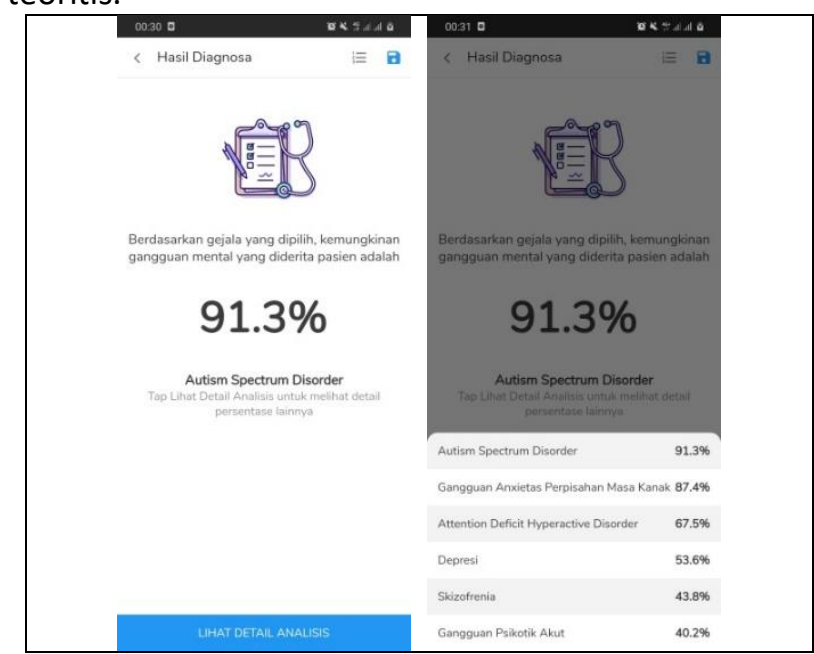

Gambar 9. Hasil pengujian perhitungan teoritis sistem

\subsection{Pengujian Akurasi}

Pengujian akurasi sistem dilakukan dilakukan dengan cara membandingkan hasil diagnosa oleh 3 pakar yaitu 3 dokter spesialis kejiwaan dengan hasil diagnosa oleh sistem berdasarkan 30 studi kasus yang sudah dikumpulkan dari hasil terjun ke lapangan. Teknis yang dilakukan saat pengujian yaitu dengan dua skenario uji perhitungan tingkat akurasi, yaitu perhitungan tingkat akurasi berdasarkan nilai belief rata-rata dari ketiga pakar dan berdasarkan nilai belief dari masing-masing pakar.

\subsubsection{Pengujian Akurasi Berdasarkan Nilai Belief Akhir}

Pengujian akurasi berdasarkan nilai akhir kepercayaan (belief) ketiga pakar (P1, P2 dan P3) dapat dilihat pada Tabel III. 
TABEL III. HASIL AKURASI SISTEM DENGAN NILAI BELIEF AKHIR

\begin{tabular}{|c|c|c|c|}
\hline $\begin{array}{c}\text { Hasil diagnosa } \\
\text { sistem }\end{array}$ & \begin{tabular}{|c|} 
Hasil diagnosa \\
P1
\end{tabular} & \begin{tabular}{|c|} 
Hasil diagnosa \\
P2
\end{tabular} & \begin{tabular}{|c|} 
Hasil diagnosa \\
P3 \\
\end{tabular} \\
\hline $\begin{array}{l}\text { Posttraumatic } \\
\text { Stress Disorder } \\
96.4 \%\end{array}$ & $\begin{array}{l}\text { Posttraumatic } \\
\text { Stress } \\
\text { Disorder }\end{array}$ & $\begin{array}{l}\text { Posttraumatic } \\
\text { Stress } \\
\text { Disorder }\end{array}$ & Depresi \\
\hline \begin{tabular}{|l|} 
Attention \\
Deficit \\
Hyperactive \\
Disorder $99.5 \%$
\end{tabular} & \begin{tabular}{|l} 
Attention \\
Deficit \\
Hyperactive \\
Disorder
\end{tabular} & $\begin{array}{l}\text { Attention } \\
\text { Deficit } \\
\text { Hyperactive } \\
\text { Disorder }\end{array}$ & \begin{tabular}{|l} 
Attention \\
Deficit \\
Hyperactive \\
Disorder
\end{tabular} \\
\hline $\begin{array}{l}\text { Skizofrenia } \\
100 \%\end{array}$ & Skizofrenia & Skizofrenia & Skizofrenia \\
\hline Depresi 99.8\% & & & \\
\hline \begin{tabular}{|l} 
Attention \\
Deficit \\
Hyperactive \\
Disorder $99.8 \%$
\end{tabular} & \begin{tabular}{|l} 
Attention \\
Deficit \\
Hyperactive \\
Disorder
\end{tabular} & \begin{tabular}{|l} 
Attention \\
Deficit \\
Hyperactive \\
Disorder
\end{tabular} & $\begin{array}{l}\text { Autism } \\
\text { Spectrum } \\
\text { Disorder }\end{array}$ \\
\hline \begin{tabular}{|l|} 
Attention \\
Deficit \\
Hyperactive \\
Disorder $99.6 \%$
\end{tabular} & \begin{tabular}{|l} 
Attention \\
Deficit \\
Hyperactive \\
Disorder
\end{tabular} & $\begin{array}{l}\text { Attention } \\
\text { Deficit } \\
\text { Hyperactive } \\
\text { Disorder }\end{array}$ & \begin{tabular}{|l} 
Attention \\
Deficit \\
Hyperactive \\
Disorder
\end{tabular} \\
\hline \begin{tabular}{|l|} 
Gangguan \\
Psikotik Akut \\
99.9\%, \\
Skizofrenia \\
99.9\% \\
\end{tabular} & Skizofrenia & $\begin{array}{l}\text { Gangguan } \\
\text { Psikotik Akut }\end{array}$ & $\begin{array}{l}\text { Gangguan } \\
\text { Psikotik Akut }\end{array}$ \\
\hline \begin{tabular}{|l} 
Gangguan \\
Anxietas \\
Perpisahan \\
Masa Kanak \\
$98.9 \%$ \\
\end{tabular} & \begin{tabular}{|l} 
Gangguan \\
Anxietas \\
Perpisahan \\
Masa Kanak
\end{tabular} & $\begin{array}{l}\text { Gangguan } \\
\text { Anxietas } \\
\text { Perpisahan } \\
\text { Masa Kanak }\end{array}$ & \begin{tabular}{|l} 
Gangguan \\
Anxietas \\
Perpisahan \\
Masa Kanak
\end{tabular} \\
\hline $\begin{array}{l}\text { Posttraumatic } \\
\text { Stress Disorder } \\
95.1 \%\end{array}$ & $\begin{array}{l}\text { Posttraumatic } \\
\text { Stress } \\
\text { Disorder }\end{array}$ & $\begin{array}{l}\text { Posttraumatic } \\
\text { Stress } \\
\text { Disorder }\end{array}$ & $\begin{array}{l}\text { Posttraumatic } \\
\text { Stress Disorder }\end{array}$ \\
\hline $\begin{array}{l}\text { Skizofrenia } \\
100 \%\end{array}$ & Skizofrenia & Skizofrenia & Skizofrenia \\
\hline
\end{tabular}

Berdasarkan hasil perhitungan yang sudah dilakukan berdasarkan hasil pengujian seperti Tabel III di atas, dapat diketahui nilai rata-rata keakuratan sistem dari pengujian akurasi antara hasil diagnosis oleh ketiga pakar dengan hasil diagnosis sistem pakar diagnosis gangguan mental pada anak dengan metode Forward Chaining dan Certainty Factor berdasarkan nilai belief rata-rata 3 pakar yaitu sebesar 91.11\%. Tabel hasil pengujian akurasi berdasarkan nilai akhir belief 3 pakar selengkapnya dapat dilihat pada tautan berikut:

https://drive.google.com/file/d/1U8a6YBssisbrvxTSFn $\underline{\mathrm{m} 1 \mathrm{csBccEXzOCrk} / \text { view? usp=sharing }}$

\subsubsection{Pengujian Akurasi Berdasarkan Nilai Belief Masing-masing Pakar}

Pengujian akurasi berdasarkan nilai kepercayaan (belief) dari pakar 1 (P1) dapat dilihat pada Tabel IV.
TABEL IV. PENGUIIAN AKURASI NILAI BELIEF PAKAR 1

\begin{tabular}{|l|l|c|}
\hline Hasil diagnosa P1 & $\begin{array}{l}\text { Hasil diagnosa sistem } \\
\text { berdasarkan nilai } \\
\text { belief P1 }\end{array}$ & Keterangan \\
\hline $\begin{array}{l}\text { Posttraumatic Stress } \\
\text { Disorder }\end{array}$ & $\begin{array}{l}\text { Posttraumatic Stress } \\
\text { Disorder 87.6\% }\end{array}$ & Valid \\
\hline $\begin{array}{l}\text { Attention Deficit } \\
\text { Hyperactive Disorder }\end{array}$ & $\begin{array}{l}\text { Attention Deficit } \\
\text { Hyperactive Disorder } \\
99.5 \%\end{array}$ & Valid \\
\hline Skizofrenia & Skizofrenia 100\% & Valid \\
\hline Depresi & Depresi 99.8\% & Valid \\
\hline $\begin{array}{l}\text { Attention Deficit } \\
\text { Hyperactive Disorder }\end{array}$ & $\begin{array}{l}\text { Attention Deficit } \\
\text { Hyperactive Disorder } \\
99.3 \%\end{array}$ & Valid \\
\hline $\begin{array}{l}\text { Attention Deficit } \\
\text { Hyperactive Disorder }\end{array}$ & $\begin{array}{l}\text { Attention Deficit } \\
\text { Hyperactive Disorder } \\
99.2 \%\end{array}$ & Valid \\
\hline Skizofrenia & Skizofrenia 99.9\% & Valid \\
\hline $\begin{array}{l}\text { Gangguan Anxietas } \\
\text { Perpisahan Masa } \\
\text { Kanak }\end{array}$ & $\begin{array}{l}\text { Gangguan Anxietas } \\
\text { Perpisahan Masa } \\
\text { Kanak 100\% }\end{array}$ & Valid \\
\hline $\begin{array}{l}\text { Posttraumatic Stress } \\
\text { Disorder }\end{array}$ & $\begin{array}{l}\text { Posttraumatic Stress } \\
\text { Disorder 90.7\% }\end{array}$ & Valid \\
\hline Skizofrenia & Skizofrenia 100\% & Valid \\
\hline Berdasarkan hasil pengujan akurasi pada Tabel IV
\end{tabular}

Berdasarkan hasil pengujian akurasi pada Tabel IV antara diagnosis sistem berdasarkan nilai belief pakar 1 dengan hasil diagnosis yang dilakukan pakar 1 terdapat 29 kasus yang sesuai dan 1 kasus tidak sesuai. Sehingga diperoleh nilai keakuratan sebesar $\frac{29}{30} \times$ $100 \%=96.6$. Tabel hasil pengujian akurasi berdasarkan nilai belief pakar 1 terhadap 30 kasus selengkapnya dapat dilihat pada tautan berikut: https://drive.google.com/file/d/16DpW26H5ysk8WJ W sOtRtQSIPKUdQG6J/view? usp=sharing Pengujian akurasi berdasarkan nilai kepercayaan (belief) dari pakar 2 (P2) dapat dilihat pada Tabel V.

TABEL V. PENGUJIAN AKURASI NILAI BELIEF PAKAR 2

\begin{tabular}{|l|l|c|}
\hline Hasil diagnosa P2 & $\begin{array}{l}\text { Hasil diagnosa sistem } \\
\text { berdasarkan nilai } \\
\text { belief P2 }\end{array}$ & Keterangan \\
\hline $\begin{array}{l}\text { Posttraumatic Stress } \\
\text { Disorder }\end{array}$ & $\begin{array}{l}\text { Posttraumatic Stress } \\
\text { Disorder 97.6\% }\end{array}$ & Valid \\
\hline $\begin{array}{l}\text { Attention Deficit } \\
\text { Hyperactive Disorder }\end{array}$ & $\begin{array}{l}\text { Attention Deficit } \\
\text { Hyperactive Disorder } \\
98.4 \%\end{array}$ & Valid \\
\hline Skizofrenia & Skizofrenia 100\% & Valid \\
\hline Depresi & Depresi 99.5\% & Valid \\
\hline
\end{tabular}


TABEL V. LANJUTAN

\begin{tabular}{|l|l|c|}
\hline Hasil diagnosa P2 & $\begin{array}{l}\text { Hasil diagnosa sistem } \\
\text { berdasarkan nilai } \\
\text { belief P2 }\end{array}$ & Keterangan \\
\hline $\begin{array}{l}\text { Attention Deficit } \\
\text { Hyperactive Disorder }\end{array}$ & $\begin{array}{l}\text { Attention Deficit } \\
\text { Hyperactive Disorder } \\
99.8 \%\end{array}$ & Valid \\
\hline $\begin{array}{l}\text { Attention Deficit } \\
\text { Hyperactive Disorder }\end{array}$ & $\begin{array}{l}\text { Attention Deficit } \\
\text { Hyperactive Disorder } \\
99.6 \%\end{array}$ & Valid \\
\hline $\begin{array}{l}\text { Gangguan Psikotik } \\
\text { Akut }\end{array}$ & $\begin{array}{l}\text { Gangguan Psikotik } \\
\text { Akut 100\%, } \\
\text { Skizofrenia 100\% }\end{array}$ & Valid \\
\hline $\begin{array}{l}\text { Gangguan Anxietas } \\
\text { Perpisahan Masa } \\
\text { Kanak }\end{array}$ & $\begin{array}{l}\text { Gangguan Anxietas } \\
\text { Perpisahan Masa } \\
\text { Kanak 97.6\% }\end{array}$ & Valid \\
\hline $\begin{array}{l}\text { Posttraumatic Stress } \\
\text { Disorder }\end{array}$ & $\begin{array}{l}\text { Posttraumatic Stress } \\
\text { Disorder 96.0\% }\end{array}$ & Valid \\
\hline Skizofrenia & Skizofrenia 100\% & Valid \\
\hline
\end{tabular}

Berdasarkan hasil pengujian akurasi pada Tabel V antara diagnosis sistem berdasarkan nilai belief pakar 2 dengan hasil diagnosis yang dilakukan pakar 2 terdapat 29 kasus yang sesuai dan 1 kasus tidak sesuai. Sehingga diperoleh nilai keakuratan sebesar $\frac{29}{30} \times$ $100 \%=96.67 \%$. Tabel hasil pengujian akurasi berdasarkan nilai belief pakar 2 terhadap 30 kasus selengkapnya dapat dilihat pada tautan berikut: https://drive.google.com/file/d/1gQOu25QkoriUT2wY 2t0lfIIBkxrOrT8y/view?usp=sharing

Pengujian akurasi berdasarkan nilai kepercayaan (belief) dari pakar 3 (P3) dapat dilihat pada Tabel VI.

TABEL VI. PENGUJIAN AKURASI NILAI BELIEF PAKAR 3

\begin{tabular}{|l|l|c|}
\hline Hasil diagnosa P3 & $\begin{array}{l}\text { Hasil diagnosa sistem } \\
\text { berdasarkan nilai } \\
\text { belief P3 }\end{array}$ & Keterangan \\
\hline Depresi & $\begin{array}{l}\text { Posttraumatic Stress } \\
\text { Disorder 99.2\% }\end{array}$ & Tidak Valid \\
\hline $\begin{array}{l}\text { Attention Deficit } \\
\text { Hyperactive } \\
\text { Disorder }\end{array}$ & $\begin{array}{l}\text { Attention Deficit } \\
\text { Hyperactive Disorder } \\
99.9 \%\end{array}$ & Valid \\
\hline Skizofrenia & Skizofrenia 100\% & Valid \\
\hline Depresi & Depresi 100\% & Valid \\
\hline $\begin{array}{l}\text { Autism Spectrum } \\
\text { Disorder }\end{array}$ & $\begin{array}{l}\text { Attention Deficit } \\
\text { Hyperactive Disorder } \\
100 \%\end{array}$ & Tidak Valid \\
\hline $\begin{array}{l}\text { Attention Deficit } \\
\text { Hyperactive } \\
\text { Disorder }\end{array}$ & $\begin{array}{l}\text { Attention Deficit } \\
\text { Hyperactive Disorder } \\
100 \%\end{array}$ & Valid \\
\hline $\begin{array}{l}\text { Gangguan Psikotik } \\
\text { Akut }\end{array}$ & $\begin{array}{l}\text { Gangguan Psikotik Akut } \\
100 \%, \text { Skizofrenia 100\% }\end{array}$ & Valid \\
\hline $\begin{array}{l}\text { Gangguan Anxietas } \\
\text { Perpisahan Masa } \\
\text { Kanak }\end{array}$ & $\begin{array}{l}\text { Gangguan Anxietas } \\
\text { Perpisahan Masa } \\
\text { Kanak 98.5\% }\end{array}$ & Valid \\
\hline
\end{tabular}

Berdasarkan hasil pengujian akurasi pada Tabel VI antara diagnosis sistem berdasarkan nilai belief pakar 3 dengan hasil diagnosis yang dilakukan pakar 3 terdapat 24 kasus yang sesuai dan 6 kasus tidak sesuai. Sehingga diperoleh nilai keakuratan sebesar $\frac{29}{30} \times$ $100 \%=96.67 \%$. Tabel hasil pengujian akurasi berdasarkan nilai belief pakar 3 terhadap 30 kasus selengkapnya dapat dilihat pada tautan berikut: https://drive.google.com/file/d/1FyaY0gEPi Fe4iwRBXHXWwvSEMtKE-R/view?usp=sharing

Berdasarkan pengujian akurasi dari dua skenario yang telah dilakukan, diperoleh nilai akhir hasil pengujian akurasi sistem berdasarkan nilai akhir belief ketiga pakar sebesar $91.11 \%$ dan nilai akhir hasil pengujian akurasi sistem berdasarkan nilai belief masing-masing pakar 1, 2, dan 3 secara berurutan yaitu sebesar 96.67\%, 96.67\%, dan $80.00 \%$. Hal ini membuktikan bahwa metode yang diusulkan pada penelitian ini sudah berhasil memberikan hasil yang baik dalam mendiagnosis suatu penyakit dan menghasilkan informasi yang tepat mengenai penyebab dan saran penanganan suatu penyakit berdasarkan 30 kasus pengujian akurasi maupun kasus yang lainnya.

Ditinjau dari akurasi sistem pakar diagnosis hama anggrek menggunakan metode Forward Chaining dan Certainty Factor memberikan hasil yang sejalan (baik) dengan penerapan sebelumnya [3]. Hal ini menunjukkan bahwa penerapan metode Forward Chaining dan Certainty Factor untuk diagnosis gangguan mental pada anak dapat memberikan akurasi yang baik yaitu lebih dari $90 \%$.

\subsection{Pengujian Mean Opinion Score (MOS)}

Pengujian ini dilakukan dengan menggunakan kuesioner yang melibatkan 35 orang responden yang terdiri dari 3 kelompok yaitu mahasiswa, masyarakat umum, dan tenaga medis dimana responden akan memberi penilaian terhadap sistem kemudian hasil penilaian akan dihitung dengan parameter MOS untuk mendapat kesimpulan hasil pengujian.

Pengujian parameter MOS yang diberikan oleh 15 responden mahasiswa memiliki tujuan yaitu untuk menguji apakah sistem memiliki kualitas yang baik atau tidak. Hasil pengujian tersebut dapat dilihat pada Tabel VII. 
TABEL VII. PENGUJIAN MOS RESPONDEN MAHASISWA

\begin{tabular}{|c|c|c|c|c|c|c|c|c|}
\hline No & Pertanyaan & $\begin{array}{l}\text { SS } \\
\text { (5) }\end{array}$ & \begin{tabular}{|c|}
$S$ \\
$(4)$ \\
\end{tabular} & $\begin{array}{l}\text { TT } \\
\text { (3) }\end{array}$ & \begin{tabular}{|l|} 
TS \\
(2) \\
\end{tabular} & \begin{tabular}{|l|} 
STS \\
$(1)$ \\
\end{tabular} & Total & Mean pi \\
\hline 1 & Pertanyaan 1 & 5 & 10 & - & - & - & 15 & 4.33 \\
\hline 2 & Pertanyaan 2 & 3 & 12 & - & - & - & 15 & 4.20 \\
\hline 3 & Pertanyaan 3 & 2 & 12 & - & 1 & - & 15 & 4.00 \\
\hline 4 & Pertanyaan 4 & 5 & 10 & - & - & - & 15 & 4.33 \\
\hline 5 & Pertanyaan 5 & 4 & 10 & 1 & - & - & 15 & 4.20 \\
\hline 6 & Pertanyaan 6 & 5 & 10 & - & - & - & 15 & 4.33 \\
\hline \multirow[t]{3}{*}{7} & Pertanyaan 7 & 2 & 11 & 2 & - & - & 15 & 4.00 \\
\hline & Sub Total & 26 & 75 & 3 & 1 & - & 105 & 29.39 \\
\hline & & & $\mathrm{MC}$ & & in & pin & Score & 4.20 \\
\hline
\end{tabular}

Keterangan:

Pertanyaan 1: Tampilan sistem pakar diagnosis gangguan mental pada anak ini menarik dan mudah digunakan

Pertanyaan 2: Tampilan sistem pakar diagnosis gangguan mental pada anak memiliki kecocokan dalam penggunaan warna, jenis huruf, dan style di setiap halaman

Pertanyaan 3: Tampilan sistem pakar diagnosis gangguan mental pada anak memiliki kecocokan antara background dan foreground

Pertanyaan 4: Sistem pakar ini dalam penggunaannya memiliki loading yang cepat (kurang dari 5 detik) pada saat fitur-fitur dijalankan

Pertanyaan 5: Informasi-informasi yang terdapat pada sistem pakar ini mudah dipahami

Pertanyaan 6: Dengan adanya sistem pakar ini dapat membantu untuk mendiagnosa gangguan mental pada anak menjadi lebih mudah

Pertanyaan 7: Di waktu yang akan datang, anda akan tetap menggunakan sistem pakar ini untuk membantu melakukan diagnosis gangguan mental pada anak

Berdasarkan hasil pengujian MOS pada Tabel VII yang diperoleh dari hasil kuesioner 15 responden mahasiswa didapatkan kesimpulan hasil perhitungan MOS sebesar 4.20 dari skala 5. Berdasarkan nilai tersebut menunjukkan bahwa dari segi kualitas sistem pakar yang dibangun sudah baik.

Pengujian parameter MOS yang diberikan oleh 15 responden masyarakat umum memiliki tujuan yaitu untuk menguji apakah sistem mudah dalam penggunaannya dan sistem akan tetap digunakan kedepannya atau tidak. Hasil pengujian tersebut dapat dilihat pada Tabel VIII.
TABEL VIII. PENGUJIAN MOS RESPONDEN MASYARAKAT UMUM

\begin{tabular}{|c|c|c|c|c|c|c|c|c|}
\hline No & Pertanyaan & $\begin{array}{l}\text { SS } \\
\text { (5) }\end{array}$ & $\begin{array}{c}5 \\
(4) \\
\end{array}$ & $\begin{array}{l}\mathrm{TT} \\
\text { (3) }\end{array}$ & \begin{tabular}{|l|} 
TS \\
(2) \\
\end{tabular} & \begin{tabular}{|l|} 
STS \\
(1) \\
\end{tabular} & Total & Mean pi \\
\hline 1 & Pertanyaan 1 & 3 & 11 & 1 & - & - & 15 & 4.13 \\
\hline 2 & \begin{tabular}{|l|} 
Pertanyaan 2 \\
\end{tabular} & 3 & 9 & 1 & 2 & - & 15 & 3.87 \\
\hline 3 & Pertanyaan 3 & 2 & 12 & 1 & - & - & 15 & 4.07 \\
\hline 4 & Pertanyaan 4 & 2 & 13 & - & - & - & 15 & 4.13 \\
\hline 5 & Pertanyaan 5 & 1 & 14 & - & - & - & 15 & 4.07 \\
\hline & Sub Total & 11 & 59 & 3 & 2 & - & 75 & 20.27 \\
\hline \multicolumn{8}{|c|}{ MOS (Mean Opinion Score) } & 4.05 \\
\hline
\end{tabular}

\section{Keterangan:}

Pertanyaan 1: Tampilan sistem pakar diagnosis gangguan mental pada anak ini menarik dan mudah digunakan

Pertanyaan 2: Tampilan sistem pakar diagnosis gangguan mental pada anak memiliki warna dan jenis huruf yang nyaman dalam penglihatan

Pertanyaan 3: Informasi-informasi yang terdapat pada sistem pakar ini mudah dipahami

Pertanyaan 4: Dengan adanya sistem pakar ini dapat membantu untuk mendiagnosa gangguan mental pada anak menjadi lebih mudah

Pertanyaan 5: Di waktu yang akan datang, anda akan tetap menggunakan sistem pakar ini untuk membantu melakukan diagnosis gangguan mental pada anak

Berdasarkan hasil pengujian MOS pada Tabel VIII yang diperoleh dari hasil kuesioner 15 responden masyarakat umum didapatkan kesimpulan hasil perhitungan MOS sebesar 4.05 dari skala 5 . Berdasarkan nilai tersebut menunjukkan bahwa sistem pakar yang dibangun mudah dalam penggunaannya dan sistem akan tetap digunakan di waktu yang akan datang.

Pengujian parameter MOS yang diberikan oleh 5 responden tenaga medis memiliki tujuan apakah informasi yang ditampilkan sistem pakar sudah tepat atau tidak. Hasil pengujian tersebut dapat dilihat pada Tabel IX.

TABEL IX. PENGUJIAN MOS RESPONDEN TENAGA MEDIS

\begin{tabular}{|c|c|c|c|c|c|c|c|c|}
\hline No & Pertanyaan & $\begin{array}{l}\text { SS } \\
\text { (5) }\end{array}$ & $\begin{array}{c}S \\
\text { (4) }\end{array}$ & $\begin{array}{l}T T \\
\text { (3) }\end{array}$ & \begin{tabular}{|l} 
TS \\
(2)
\end{tabular} & \begin{tabular}{|l} 
STS \\
(1)
\end{tabular} & Total & Mean $p$ \\
\hline 1 & Pertanyaan 1 & - & 5 & - & - & - & 5 & 4.00 \\
\hline 2 & Pertanyaan 2 & - & 5 & - & - & - & 5 & 4.00 \\
\hline 3 & Pertanyaan 3 & - & 5 & - & - & - & 5 & 4.00 \\
\hline 4 & Pertanyaan 4 & 1 & 4 & - & - & - & 5 & 4.20 \\
\hline 5 & Pertanyaan 5 & 1 & 4 & - & - & - & 5 & 4.20 \\
\hline 6 & Pertanyaan 6 & 1 & 4 & - & - & - & 5 & 4.20 \\
\hline & Sub Total & 3 & 27 & - & - & - & 30 & 24.60 \\
\hline \multicolumn{8}{|c|}{ MOS (Mean Opinion Score) } & 4.10 \\
\hline
\end{tabular}

Keterangan:

Pertanyaan 1: Tampilan sistem pakar diagnosis gangguan mental pada anak ini menarik dan mudah digunakan 
Pertanyaan 2: Tampilan sistem pakar diagnosis gangguan mental pada anak memiliki warna dan jenis huruf yang nyaman dalam penglihatan

Pertanyaan 3: Sistem pakar ini menampilkan jenis-jenis penyakit beserta gejala dan penanganannya yang sesuai dengan ilmu yang terdapat di bidang kedokteran

Pertanyaan 4: Dengan adanya sistem pakar ini dapat memberikan informasi penanganan gangguan mental pada anak yang tepat

Pertanyaan 5: Dengan adanya sistem pakar ini dapat membantu untuk mendiagnosa gangguan mental pada anak menjadi lebih mudah

Pertanyaan 6: Di waktu yang akan datang, anda akan tetap menggunakan sistem pakar ini untuk membantu melakukan diagnosis gangguan mental pada anak

Berdasarkan hasil pengujian MOS pada Tabel IX yang diperoleh dari hasil kuesioner 5 responden tenaga medis didapatkan kesimpulan hasil perhitungan MOS sebesar 4.10 dari skala 5. Berdasarkan nilai tersebut menunjukkan bahwa sistem pakar yang dibangun menghasilkan informasi yang tepat mengenai gangguan mental pada anak.

Dari penilaian masing-masing responden terhadap sistem pakar diagnosa gangguan mental pada anak ini diperoleh rata-rata sebesar 4.12. Pernyataan hasil kualitas sistem dengan rentang nilai MOS 4 sampai dengan 5 dikelompokkan ke dalam kategori sistem good (baik). Hal ini menunjukkan bahwa kualitas sistem pakar diagnosis gangguan mental pada anak dengan metode Forward Chaining dan Certainty Factor yang dibangun sudah baik, sistem yang dihasilkan sesuai dengan tujuan untuk memudahkan pengguna dalam mendiagnosis gangguan mental anak, dan sistem juga dapat tetap digunakan oleh masyarakat di waktu yang akan datang untuk membantu melakukan diagnosis gangguan mental pada anak.

\section{KESIMPULAN DAN SARAN}

\subsection{Kesimpulan}

Berdasarkan hasil analisis dan pengujian terhadap sistem pakar untuk mendiagnosis gangguan mental pada anak dengan metode Forward Chaining dan Certainty Factor, maka dapat diperoleh kesimpulan yaitu sebagai berikut:

a. Berdasarkan hasil pengujian akurasi sistem dengan 30 studi kasus yang diujikan oleh 3 orang pakar, sistem pakar yang dibangun berhasil menghasilkan nilai keakuratan sistem berdasarkan nilai akhir belief ketiga pakar, berdasarkan nilai belief dari pakar 1, 2, dan 3 secara berurutan sebesar $91.11 \%, 96.67 \%$, $96.67 \%$ dan $80 \%$.

b. Berdasarkan hasil pengujian MOS (Mean Opinion Score) yang dilakukan, didapatkan nilai MOS sebesar 4.12 dari skala 5 yang menunjukkan bahwa sistem dikelompokkan ke dalam kategori sistem good (baik).

\subsection{Saran}

Berdasarkan hasil penelitian sistem pakar untuk mendiagnosis gangguan mental pada anak dengan metode Forward Chaining dan Certainty Factor yang telah dilakukan, maka untuk pengembangan penelitian selanjutnya terdapat beberapa saran yaitu sebagai berikut:

a. Sistem pakar diagnosis gangguan mental pada anak ini diharapkan dapat diimplementasikan kembali dengan metode yang berbeda, seperti metode Backward Chaining, Naïve Bayes, Dempster Shafer, dan metode lainnya agar dapat dilihat perbandingan dari metode tersebut untuk menentukan metode mana yang lebih tepat untuk mendiagnosis gangguan mental pada anak.

b. Sistem pakar diagnosis gangguan mental pada anak ini diharapkan dapat dikembangkan untuk penambahan fitur CRUD (create, update, dan delete) pada basis pengetahuan.

\section{UCAPAN TERIMA KASIH}

Ucapan terima kasih yang setulus-tulusnya penulis berikan kepada Rumah Sakit Jiwa Mutiara Sukma Provinsi NTB yang telah memberikan ruang kepada penulis untuk melakukan penelitian, kepada $\mathrm{dr}$. Qomarul Islamiyati, Sp.KJ, dr. Agustine M. M.Kes.,Sp.KJ. dan dr. Lusiana W., Sp.KJ selaku pakar 1, 2 , dan 3 yang telah meluangkan waktu untuk memberikan ilmunya sampai penelitian ini selesai. Dan kepada semua pihak yang tidak bisa disebutkan satu per satu karena telah membantu dalam penelitian ini.

\section{DAFTAR PUSTAKa}

[1] S. Isfandari and Suhardi, "Gejala Gangguan Mental Emosional pada Anak," Bulan Penelit. Kesehat., vol. 25, pp. 53-60, 1997.

[2] A. Supiandi and D. B. Chandradimuka, "Sistem Pakar Diagnosa Depresi Mahasiswa Akhir Dengan Metode Certainty Factor Berbasis Mobile," J. Inform., vol. 5, no. 1, pp. 102-111, 2018.

[3] D. T. Yuwono, A. Fadlil, and Sunardi, "Penerapan Metode Forward Chaining dan Certainty Factor pada Sistem Pakar Diagnosa Hama Anggrek 
Coelogyne Pandurata," Kumpul. J. IImu Komput., vol. 04, no. 02, pp. 136-145, 2017.

[4] L. Aryanti, A. Y. Husodo, and A. Zubaidi, "Analisis Penerapan Metode Bayesian Network Untuk Mendiagnosa Penyakit Gangguan Mental pada Anak," J-Cosine, pp. 1-9, 2017.

[5] D. Hastari and F. Bimantoro, "Sistem Pakar untuk Mendiagnosis Gangguan Mental Anak Menggunakan Metode Dempster Shafer," JCosine, vol. 2, no. 2, pp. 72-79, 2018.

[6] C. Susanto, "Aplikasi Sistem Pakar untuk Gangguan Mental pada Anak dengan Metode Certainty Factor," J. Pekommas, vol. 18, no. 1, pp. 27-36, 2015.

[7] M. Syarief, N. Prastiti, and W. Setiawan, "Comparison of Naïve Bayes and Certainty Factor Method for Corn Disease Expert System : Case in Bangkalan , Indonesia," J. Eng. Res. Appl., vol. 7, no. 11, pp. 30-34, 2017.

[8] P. S. Ramadhan, U. Fatimah, and S. Pane, "Analisis Perbandingan Metode ( Certainty Factor , Dempster Shafer dan Teorema Bayes ) untuk Mendiagnosa Penyakit Inflamasi Dermatitis Imun pada Anak," Sains dan Komput., vol. 17, no. 2, pp. 151-157, 2018.

[9] T. N. Oktavia, D. H. Satyareni, and E. N. Jannah, "Rancang Bangun Sistem Pakar Untuk Mendiagnosis Gangguan Kepribadian Histerik
Menggunakan Metode Certainty Factor," J. IIm. Teknol. Sist. Inf., vol. 1, no. 1, pp. 15-23, 2015.

[10] P. Windriyani, Wiharto, and S. W. Sihwi, "Expert System for Detecting Mental Disorder with Forward Chaining Method," J. Informatics Dep. Sebel. Maret Univ., 2010.

[11] Turban, J. E. A. Efraim, and P. L. Ting, Decision Support Systems and Intelligent Systems. Andi Offset, 2005.

[12] M. Arhami, Konsep Dasar Sistem Pakar. Yogyakarta: Andi, 2005.

[13] Kusrini, Sistem Pakar Teori dan Aplikasi. Yogyakarta: Andi, 2006.

[14] K. Andrean, H. Armanto, and C. Pickerling, "Sistem Tempat Parkir Terintegrasi yang Dilengkapi dengan Aplikasi Mobile dan Mikrokontroller," J. Inf. Syst. Hosp. Technol., vol. 2, no. 01, pp. 22-29, 2020.

[15] K. Ramadhan and A. Utami, "Sistem Informasi Kelulusan dan Kriptografi ljasah pada Lembaga Pendidikan Penerbangan," Manaj. Inform., vol. 9, no. 2, pp. 136-143, 2019.

[16] A. Rosana MZ, "Sistem Pakar Diagnosa Penyakit Kulit pada Manusia dengan Metode Dempster Shafer," 2019. 